\title{
Functional Bone Engineering Using ex Vivo Gene Therapy and Topology-Optimized, Biodegradable Polymer Composite Scaffolds
}

\author{
CHIA-YING LIN, Ph.D., ${ }^{1}$ RACHEL M. SCHEK, Ph.D., ${ }^{2}$ AMIT S. MISTRY, B.S., ${ }^{3}$ \\ XINFENG SHI, M.S., ${ }^{3}$ ANTONIOS G. MIKOS, Ph.D., ${ }^{3}$ PAUL H. KREBSBACH, D.D.S., Ph.D., ${ }^{2}$ \\ and SCOTT J. HOLLISTER, Ph.D. ${ }^{1}$
}

\begin{abstract}
Bone tissue engineering could provide an alternative to conventional treatments for fracture nonunion, spinal fusion, joint replacement, and pathological loss of bone. However, this approach will require a biocompatible matrix to allow progenitor cell delivery and support tissue invasion. The construct must also support physiological loads as it degrades to allow the regenerated tissue to bear an increasing load. To meet these complex requirements, we have employed topology-optimized design and solid free-form fabrication to manufacture biodegradable poly(propylene fumarate)/ $\boldsymbol{\beta}$-tricalcium phosphate composites. These scaffolds were seeded with primary human fibroblasts transduced with an adenovirus expressing bone morphogenetic protein- 7 and implanted subcutaneously in mice. Specimens were evaluated by microcomputed tomography, compressive testing, and histological staining. New bone was localized on the scaffold surface and closely followed its designed contours. Furthermore, the total stiffness of the constructs was retained for up to 12 weeks after implantation, as scaffold degradation and tissue invasion took place.
\end{abstract}

\section{INTRODUCTION}

Qeveral clinical situations, including fracture nonunion, spinal fusion, joint replacement, and pathological loss of bone, could all be improved by the ability to tissue engineer bone. ${ }^{1-6}$ It has been well established that tissue engineering requires an appropriate matrix that is biodegradable and biocompatible, allows for delivery of appropriate progenitor cells or biofactors, and supports the invasion of the desired tissue and blood supply. ${ }^{7-9}$ For bone tissue engineering, however, the need to maintain adequate mechanical properties to perform properly in a load-bearing site adds another level of complex- ity. ${ }^{10-12}$ This performance requires compressive strength great enough to bear the load, but low enough to not greatly exceed that of the adjacent bone tissue, as this may trigger stress shielding and subsequent bone resorption. Furthermore, as the scaffold degrades and its mechanical properties decline, the physiological forces must be transferred to the regenerated tissue. ${ }^{10}$ In this dynamic situation, designing scaffolds that possess appropriate mechanical properties and allow tissue ingrowth can be greatly improved by computational scaffold optimization and fabrication. ${ }^{13}$

Much of bone tissue engineering and, indeed, tissue engineering in general, currently employs scaffolds made

\footnotetext{
${ }^{1}$ Department of Biomedical Engineering, University of Michigan, Ann Arbor, Michigan.

${ }^{2}$ School of Dentistry, University of Michigan, Ann Arbor, Michigan.

${ }^{3}$ Department of Bioengineering, Rice University, Houston, Texas.
} 
by techniques such as gas foaming and salt leaching. ${ }^{14-21}$ These methods create highly porous scaffolds that have been used to engineer a variety of tissues. ${ }^{22-25}$ However, the internal features and the interconnectivity of created pores/conduits cannot be designed a priori. In addition, these methods do not allow for the creation of complex external geometries that could match anatomical defect sites; branching structures; or complex, oriented internal pore geometry. The lack of well-defined internal topology may be a barrier to proper tissue penetration. We have developed computational scaffold optimization techniques the can overcome these limitations. ${ }^{26,27}$ They allow for design of a scaffold that simultaneously possesses load-bearing capacity and interconnected designed porosity, which allows biofactor delivery and mechanical stimulation of regenerated tissue. Topology optimization is a design technique that provides optimal distribution of material under applied force to satisfy the objective of maximal stiffness with desired porosity, under constraints of the design criteria. ${ }^{26-29}$ This approach addresses the conflicting design issues of having sufficient load-bearing capability while at the same time having enough interconnected porosity to deliver biofactors such as cells, genes, and proteins and to impart sufficient mechanical strain to maintain developing tissue.

These topology-optimized scaffolds can then be manufactured by indirect solid free-form fabrication (SFF). ${ }^{13,30,31}$ Indirect SFF employs the fabricated structures as molds and allows the creation of scaffolds from a large number of materials. ${ }^{31-33}$ This technique allows the creation of scaffolds with designed external and internal geometry cast from a biodegradable composite of poly(propylene fumarate) incorporating $\beta$-tricalcium phosphate $(\mathrm{PPF} / \beta-\mathrm{TCP})$. $\mathrm{PPF} / \beta-\mathrm{TCP}$ is a promising new material for the tissue engineering of bone for several reasons. It has been postulated that the mechanical properties of this composite increase during the early stage of degradation by means of a reinforcement mechanism, most likely due to continued cross-linking, and also by forming complexes of polymeric carboxylic acid groups with calcium ions. ${ }^{34-36}$ This continued stiffness increase before degradation, along with the lack of acidic degradation products from commonly used poly $(\alpha$-hydroxy esters), may make PPF/ $\beta$-TCP more suitable for load-bearing orthopedic applications. It has also been shown that $\mathrm{PPF} / \beta$-TCP substrates provide an osteoconductive surface that facilitates the proliferation and differentiation of marrow stromal osteoblasts. ${ }^{37}$

To effectively engineer bone, scaffolds must be seeded with appropriate progenitor cells or growth factors. Gene therapy may provide an alternative to these options, without the need for large amounts of expensive recombinant proteins or progenitor cells that may be difficult to harvest and expand. It has been previously shown that easily harvested and expanded cells may be transduced to express factors that initiate bone formation. ${ }^{38-41}$ This socalled ex vivo gene therapy approach has been shown to trigger ectopic bone formation and healing of segmental and cranial defects in animal models. ${ }^{38,40}$ Such transduced cells have already shown promise in producing bone on porous designed scaffolds. ${ }^{42}$

In this study, we combined ex vivo gene therapy with designed, solid free-form fabricated scaffolds to regenerate a functional bone construct. Topology-optimized composite scaffolds made from PPF/ $\beta$-TCP were seeded with human fibroblasts transduced to express bone morphogenetic protein-7 (BMP-7). After ectopic implantation in a murine model, the scaffolds were evaluated mechanically and histologically, and by microcomputed tomography. These data allowed us to evaluate the quantity and quality of bone produced by this combined approach. In addition, we have evaluated the dynamic mechanical properties of the implants as bone invaded the scaffold and the PPF/ $\beta$-TCP degraded. The results demonstrated that the integration of computational optimization, indirect SFF using a biodegradable $\mathrm{PPF} / \beta$-TCP composite, and ex vivo gene therapy produced a functional osteogenic construct for bone tissue engineering.

\section{MATERIALS AND METHODS}

\section{Design and manufacture of scaffolds}

A hierarchical integrated topology optimization technique accounting for degradation was used to design the scaffolds as previously described. ${ }^{26}$ Briefly, the optimization method creates a density distribution map within the design domain that accommodates the subcutaneous scale with dimensions of $6 \mathrm{~mm}$ in diameter and $4 \mathrm{~mm}$ in height, for selected time points during degradation. These different density distributions are then superposed, using both time-lasting and time-degrading modulus weighting factors. This forms the basis of the macroscopic or first hierarchical scale-optimized topology to provide the general density and location of material within the design domain. The microscopic or second-scale topology optimization approach gives the specific microstructure design that achieves a desired compliance while matching the predicted volume fraction of the macroscopic or first-level topology optimization. $^{26,27}$ The final scaffold design was $50 \%$ porous with pore sizes ranging from 300 to $1000 \mu \mathrm{m}$. The entire scaffold design can then be generated by assigning the designed microstructures to the corresponding global density layout (Fig. 1).

Fifty-six wax molds of the designed scaffolds were fabricated on a ModelMaker II three-dimensional rapid prototyping system (Solidscape, Merrimack, NH). A paste was generated by dissolving $1.0 \mathrm{~g}$ of synthesized 


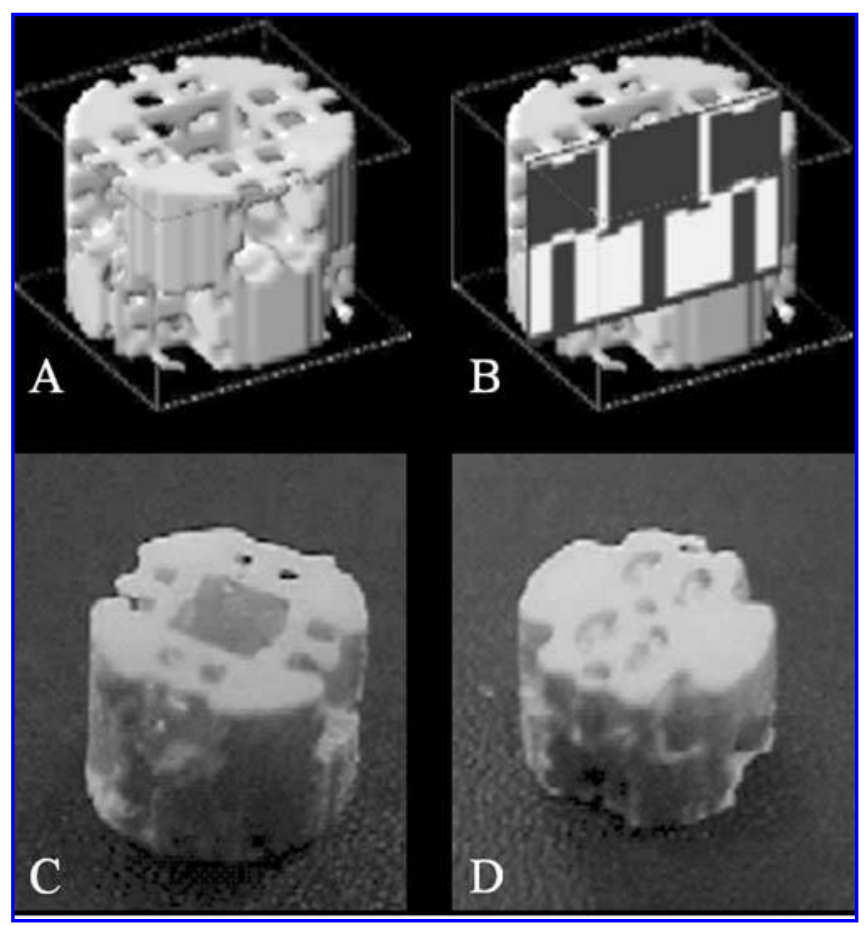

FIG. 1. Topology optimization was used to design the scaffold (A) and it internal architecture (B). This design was faithfully produced in the fabricated PPF/ $\beta$-TCP scaffold [top (C) and bottom (D)].

PPF (MW, 1500 Da; polydispersity index, 2.2) ${ }^{35,43}$ and $0.02 \mathrm{~g}$ of the initiator benzoyl peroxide (Sigma, St. Louis, $\mathrm{MO})$ in $1.0 \mathrm{~mL}$ of the monomer $N$-vinyl pyrrolidinone (Sigma). After complete dissolution, $0.6 \mathrm{~g}$ of $\beta$-TCP (Plasma Biotal, North Derbyshire, UK) was added. Finally, $1 \mu \mathrm{L}$ of the accelerator $N, N$-dimethyl- $p$-toluidene (Sigma) was added just before casting to induce crosslinking. This PPF/ $\beta$-TCP paste was forced into the molds. After casting, molds were held in a nitrogen chamber at room temperature for $24 \mathrm{~h}$. The samples were then treated with acetone (Fisher Scientific, Fair Lawn, NJ) to dissolve the molds. The scaffolds were subsequently rinsed in distilled water for $24 \mathrm{~h}$ and then sterilized in $70 \%$ ethanol (Fisher Scientific) for $24 \mathrm{~h}$.

\section{Seeding and implantation}

Primary human gingival fibroblasts were prepared from explants of human surgical waste in compliance with the University of Michigan (Ann Arbor, MI) Institutional Review Board. Primary explants of gingival fibroblasts were expanded in $\alpha$-minimum essential medium ( $\alpha$-MEM) containing $10 \%$ fetal bovine plasma and $1 \%$ penicillin-streptomycin (GIBCO; Invitrogen, Frederick, MD). ${ }^{44}$ Passage 4 fibroblasts were infected with AdCMV-BMP-7, a first-generation recombinant adenovirus construct expressing the murine BMP-7 gene under the control of the cytomegalovirus (CMV) promoter. The virus was created by Cre-lox recombination as previously described. ${ }^{45}$ Cells thus infected have been previously shown to express BMP-7 in vitro, trigger ectopic bone formation, and heal critically sized murine cranial defects. ${ }^{38,41,45}$ Infections were performed overnight with 200 plaque-forming units per cell. Cells were seeded in a $2-\mathrm{mg} / \mathrm{mL}$ collagen gel made from acid-solubilized rat tail collagen (BD Biosciences Discovery Labware, Bedford, MA) diluted in phosphate-buffered saline (GIBCO), adjusted to $\mathrm{pH} 7.0$ with $1 \mathrm{~N} \mathrm{NaOH}$ (Sigma). The scaffolds were placed in tight-fitting molds and 30 $\mu \mathrm{L}$ of the collagen containing 2 million cells was pipetted into each scaffold. Scaffolds were then placed in a $37^{\circ} \mathrm{C}$ incubator for $20 \mathrm{~min}$ to allow gelation of the collagen.

Twenty-four scaffolds seeded with virally transduced fibroblasts, 8 scaffolds seeded with untransduced fibroblasts, and 24 scaffolds without cells were implanted subcutaneously into 5- to 8-week-old immunocompromised mice (N:NIH-bg-nu-xid; Charles River, Wilmington, MA). Animals were anesthetized with intraperitoneal injections of ketamine-xylazine (50 and $5 \mu \mathrm{g} / \mathrm{g}$, respectively) in saline. Subcutaneous pockets were created by blunt dissection and four scaffolds were inserted into each mouse. Surgical sites were closed with wound clips. 


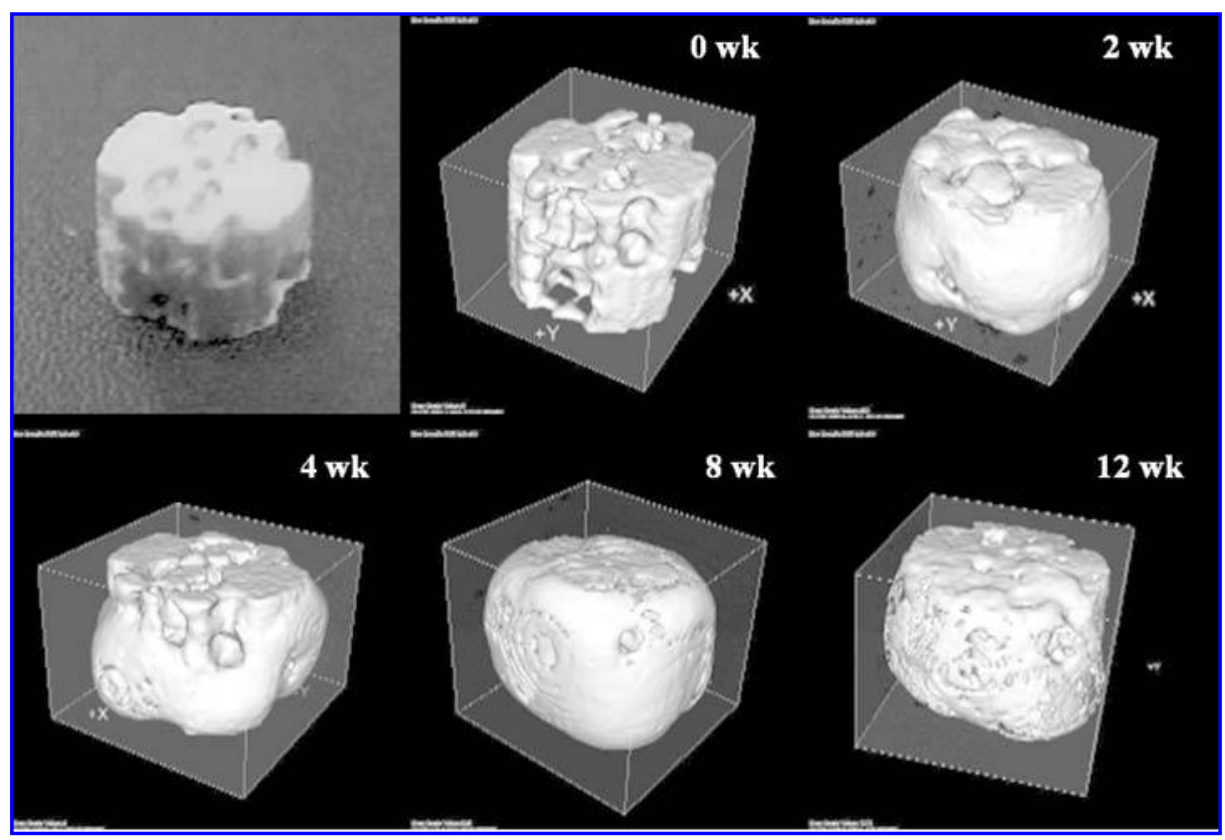

FIG. 2. $\mu \mathrm{CT}$ data were used to create three-dimensional surface renderings. A photograph of the scaffold (top left) and a scan of a scaffold that was not implanted (week 0) are provided for comparison. The renderings show an increase in bone volume at 2 weeks, followed by a slight decrease at 4 weeks. Full coverage of the scaffold by bone was observed at 8 weeks. Somewhat less bone appeared to be covering the scaffold after 12 weeks than after 8 weeks.

\section{Evaluation of scaffolds and generated tissue}

Mice were killed after 2, 4, 8, or 12 weeks. The harvested implants were fixed with Z-Fix (Anatech, Battle Creek, MI) and stored in $70 \%$ ethanol for microcomputed tomography $(\mu \mathrm{CT})$ analysis. Specimens were scanned by $\mu \mathrm{CT}$ in water, using an MS-130 high-resolution MicroCT scanner (GE Medical Systems, London, ON, Canada) at $15-\mu \mathrm{m}$ voxel resolution and $75 \mathrm{kV}$. Three-dimensional isosurface renderings were made with MicroView version 1.1.1 (GE Medical Systems). Image threshold levels were automatically calculated by applying the autothreshold algorithm from the histogram presented in MicroView, and volume fractions of the scanned scaffolds were thus generated. Because of the difficulty in extracting new-forming bone tissue from the new constructs, resulting from the identical gray-scale density of calcified bone tissue with $\beta$-tricalcium phosphate in the scaffold composite, total solid volumes of empty scaffolds and tissue caffold constructs were calculated by multiplying the volume of the defined region of interest by individual volume fractions. Last, regenerated bone volumes were calculated by subtracting the average volumes of empty scaffolds from those of tissue caffold constructs.

After $\mu \mathrm{CT}$ scanning, histological evaluation was conducted on three of the cell-seeded scaffolds and one of the empty scaffolds from each implantation time. These scaffolds were demineralized with RDO (Apex Engineering Products, Aurora, IL). ${ }^{31}$ The scaffolds were then

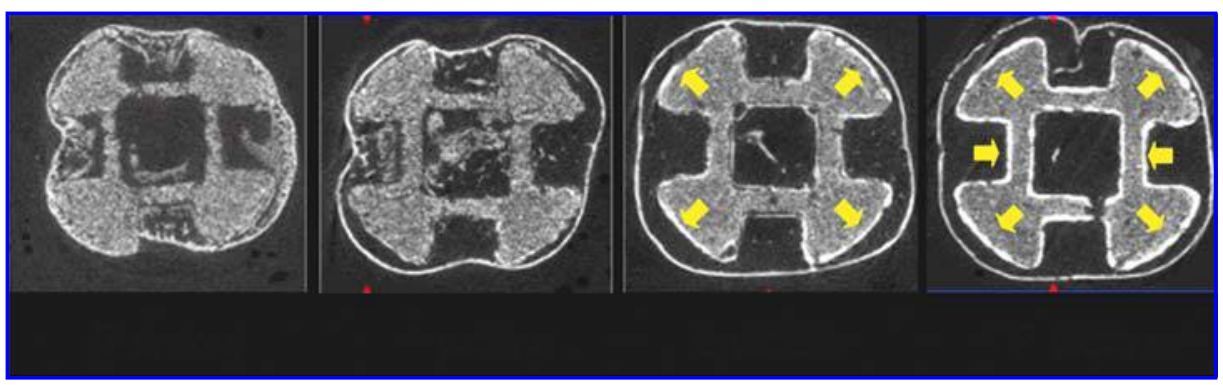

FIG. 3. Cross-sections of the $\mu \mathrm{CT}$ data reveal increased bone apposition $2,4,8$, and 12 weeks postimplantation. As implantation time increased, bone was more highly localized, closely following the scaffold contours (arrows). 
embedded in paraffin, sectioned at $7 \mu \mathrm{m}$, and stained with hematoxylin and eosin (H\&E).

A subset of scaffolds was not demineralized and was subjected to mechanical testing. A 0.5 -lb preload was applied followed by a compressive test to failure at a crosshead speed of $1 \mathrm{~mm} / \mathrm{min}$ (ASTM D695-02a; Standard Test Method for Compressive Properties of Rigid Plastics), using an MTS Alliance RT30 electromechanical test frame (MTS Systems, Eden Prairie, MN). The compression test was continued until failure, when a drop took place in the real-time compressive load-displacement curve. Load versus deflection was continuously monitored and recorded, and values of peak load and effective compressive moduli, defined as the slope of the linear region at the stress-strain curve, were then calculated by the system.

\section{RESULTS}

The fabrication of PPF/ $\beta$-TCP scaffolds showed that the mold-casting process successfully reproduced features from the original designs (Fig. 1). Scaffolds were seeded with BMP-7-transduced or untreated human fibroblasts or left empty. After subcutaneous implantation in mice for $2,4,8$, or 12 weeks, the scaffolds were removed and fixed. Three-dimensional surface rendering of reconstructed scanned $\mu \mathrm{CT}$ images showed that no bone was observed on empty scaffolds or on scaffolds seeded with untransduced fibroblasts. However, increased accumulation of bone over time was noted on those scaffolds seeded with transduced fibroblasts (Fig. 2). After 2 weeks in vivo, new bone had formed and covered the scaffold along the designed contours. At 4 weeks, the covering area decreased. Interestingly, a circumferential pattern of conduits started to form on the forming bone shell. After 8 weeks, the circumferential pattern had progressed and covering of cortical bone was observed around a large portion of the scaffold. After 12 weeks, however, a loss of bone was apparent on the three-dimensional image of the construct. The layer of cortical bone that existed at earlier implantation times became less dense, with disconnected bone fragments. Cross-sectional images of the $\mu \mathrm{CT}$ data showed bone infiltration in the circumferential channels at 2 weeks, and infiltration into the center well at 4 weeks (Fig. 3). The apposition of new bone increased progressively along the designed contours as implantation time lengthened. Interestingly, the bone localized on the scaffold contours became thicker and appeared brighter in the CT images. The data from the $\mu \mathrm{CT}$ scans were used to calculate bone volume and showed little change in bone volume (Table 1). Changes in bone formation after increased implantation times were reflected largely in the geometry of the bone.

After $\mu \mathrm{CT}$ scanning of all implants, three cell-seeded scaffolds and one empty scaffold from each implantation time were decalcified, embedded in paraffin, sectioned, and stained with H\&E (Fig. 4). Histological sections corroborated the $\mu \mathrm{CT}$ data shown in Fig. 3. Specifically, $\mathrm{H} \& \mathrm{E}$ staining demonstrated, at low magnification, increased formation of bone over 2, 4, and 8 weeks, and a slight loss of bone after 12 weeks. These sections also revealed additional morphological features of the newly formed tissue. After a 2-week implantation, a thin exterior cortex of bone surrounded a large quantity of fibrous tissue. Bone at this point remained fairly unorganized. At the 4-week point, a larger quantity of bone was observed, somewhat more organized, and marrow was present. Compared with the 2 -week specimens, the 4-week specimen clearly formed bone and more deeply penetrated the scaffold. The progression of increased organization, bone volume, and bone penetration continued at week 8 . Finally, after 12 weeks the bone remained organized, but bone volume diminished slightly. However, the cortical bone appeared thicker and located increasingly around the interior pores. Scaffolds were sliced along the longitudinal axis of the scaffold at 8 weeks to determine whether the bright rims on the $\mu \mathrm{CT}$ scan around the designed contour were due to calcium binding on the composite or to actual bone forming on the scaffold surface. The histology revealed that these bright rims were indeed

Table 1. Microcomputed Tomography Used to Calculate Bone Volume ${ }^{a}$

\begin{tabular}{lcrrrr}
\hline & \multicolumn{4}{c}{ Bone volume $\left(\mathrm{mm}^{3}\right)$} \\
\cline { 2 - 6 } & Week 0 & Week 2 & Week 4 & Week 8 & Week 12 \\
\hline Bone-scaffold construct & $45.80 \pm 1.51^{\mathrm{b}}$ & $55.28 \pm 5.23$ & $53.88 \pm 2.91$ & $55.33 \pm 4.12$ & $52.66 \pm 3.40$ \\
Effective bone $^{c}$ & & $11.21 \pm 5.23$ & $8.08 \pm 2.91$ & $9.53 \pm 4.12$ & $6.86 \pm 3.40$ \\
\hline
\end{tabular}

aBone volume changed only slightly with time, and was not found to be significant at the $95 \%$ confidence interval.

bThe average volume of empty scaffolds.

${ }^{\mathrm{c}}$ For each specimen, effective bone volume is defined as (volume of bone-scaffold construct) - (average volume of empty scaffolds). 


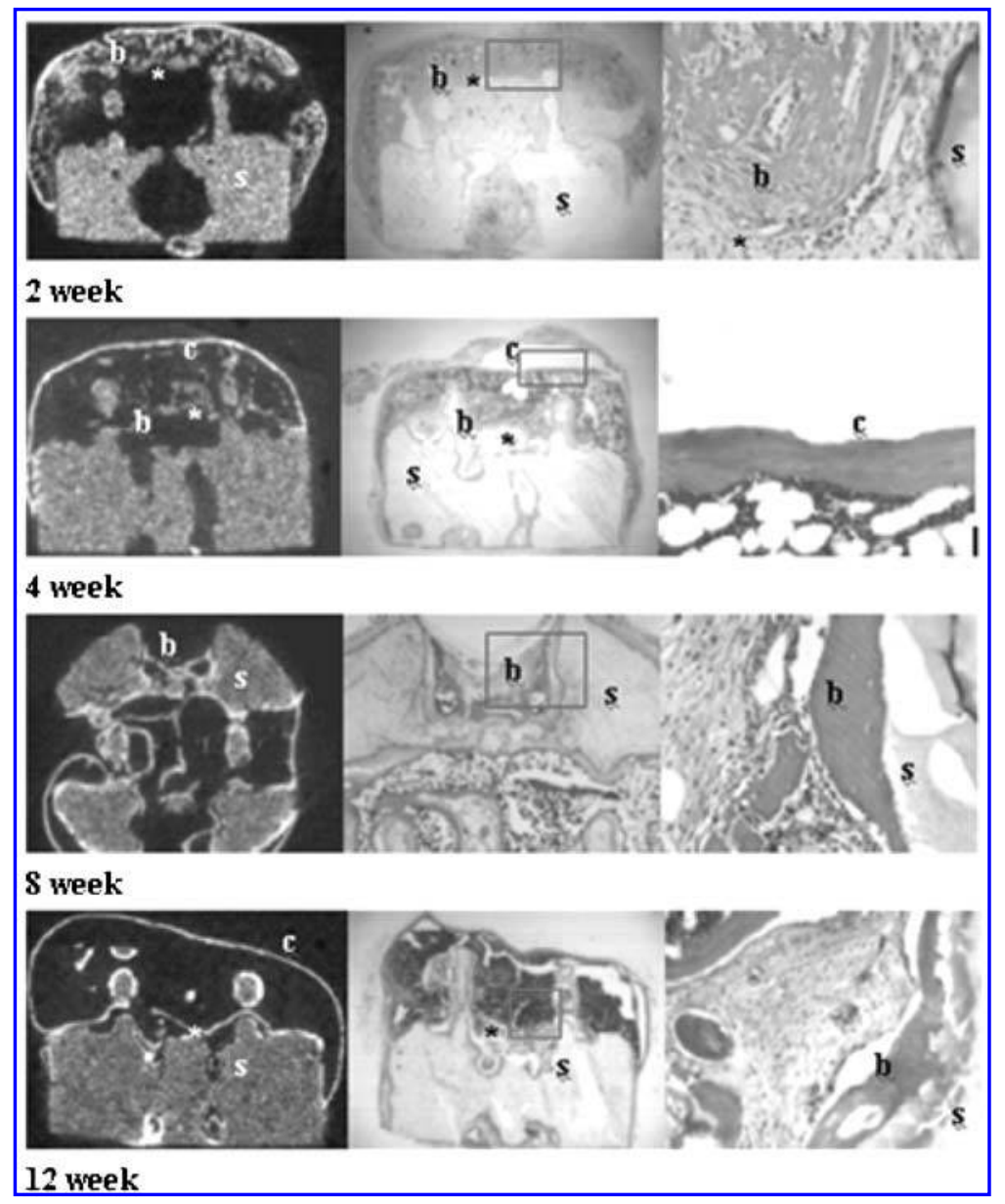

FIG. 4. Middle and right: Hematoxylin and eosin staining confirmed the presence of bone (b), in agreement with that shown in the matched $\mu \mathrm{CT}$ reconstructions (left). Middle: Low-magnification images $(\times 2)$ show trabecular bone (b), a layer of cortical bone surrounding the scaffold (c), and the residual scaffold material (s). A "front" of bone (*) was observed to progress deeper into the scaffold interior with increasing implantation times. Right: Higher magnifications $(\times 40)$ of the red-outlined areas reveal normal morphological formation of bone with marrow.

compact bone tissue deposited on the surface of osteoconductive PPF/ $\beta$-TCP composite. As in the $\mu \mathrm{CT}$ scans, only fibrous tissue was observed on the scaffolds seeded with untreated fibroblasts. These scaffolds were not included in any the subsequent mechanical testing.

For each experimental group, all those scaffolds not histologically evaluated (that is, three scaffolds seeded with cells and five empty scaffolds) were subjected to mechanical testing to determine compressive modulus and peak load. Continuously decreasing compressive modulus was observed with empty scaffolds, demonstrating in vivo degradation through the entire implantation time. However, the total compressive modulus of bone caffold constructs remained at a plateau level of $60 \mathrm{MPa}$, indicating that bone growing through the scaffold reinforced the construct and compensated for the degrading scaffold modulus (Fig. 5). The effective compressive modulus of the regenerated bone was cal- culated by directly subtracting the average compressive modulus of empty scaffolds from that of the construct at each time point, resulting in $7.89 \pm 0.97 \mathrm{MPa}$, $18.02 \pm 2.12 \mathrm{MPa}(p<0.05), 33.80 \pm 16.46 \mathrm{MPa}$, and $24.04 \pm 0.30 \mathrm{MPa}(p<0.05)$ at $2,4,8$, and 12 weeks, respectively. The ultimate load-carrying capacity was defined by the peak load that failed the specimen under uniaxial compression. The peak loads were $113.13 \pm 8.33,86.08 \pm 20.07,103.09 \pm 18.89$, and $80.88 \pm 21.17 \mathrm{~N}$ at $2,4,8$, and 12 weeks, respectively. The effective peak loads on regenerated bone were then calculated by subtracting the average peak loads of empty scaffolds $(56.31,54.50,30.11$, and $42.03 \mathrm{~N}$ ) from that of the construct at each time point. Therefore, the effective peak loads on bone regenerated at each predetermined time point were $56.82 \pm 8.33$, $43.18 \pm 0.58,72.99 \pm 18.89$, and $50.57 \pm 8.57 \mathrm{~N}$ at 2 , 4,8 , and 12 weeks, respectively. At the $95 \%$ confi- 


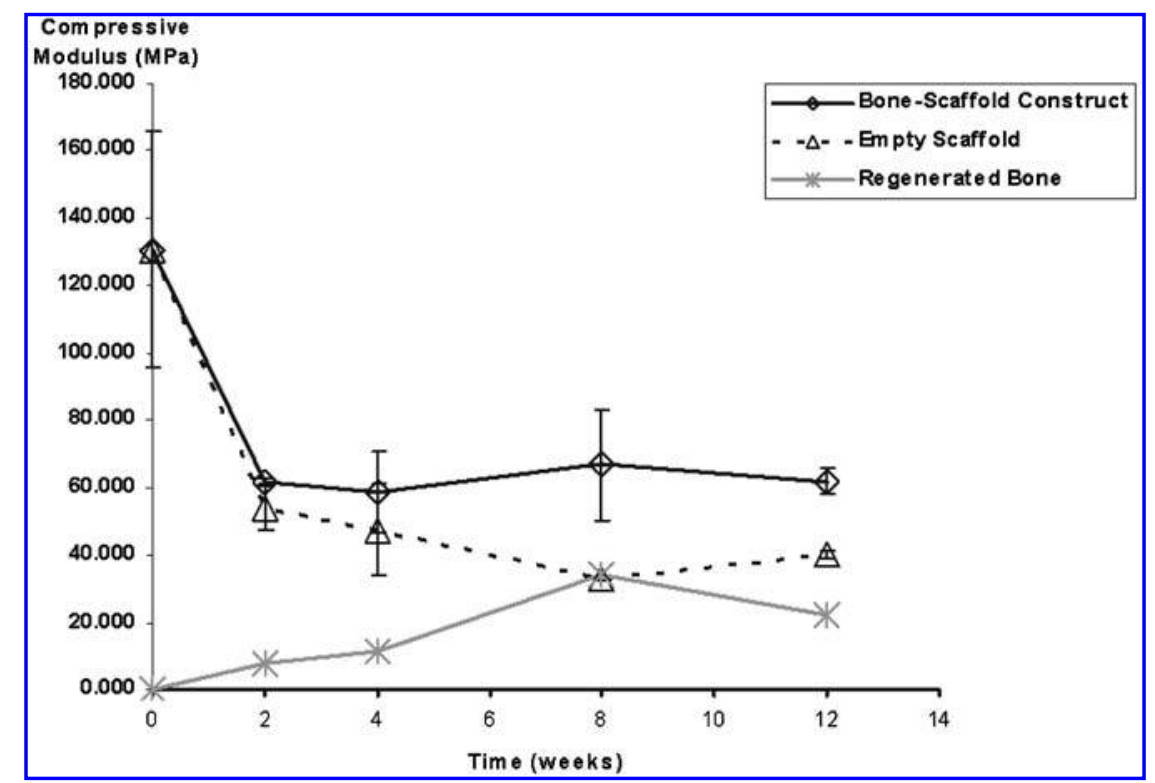

FIG. 5. Over increasing implantation times, the compressive modulus of the scaffold declined and the modulus of the tissue increased. These simultaneous phenomena resulted in a modulus for the entire construct that was nearly constant.

dence interval, no significance was found for the difference between effective peak loads over time.

\section{DISCUSSION}

Effective tissue engineering of a load-bearing tissue such as bone requires a scaffold with appropriate mechanical properties that endure until the regenerated bone can carry load. In an ideal system, cells would differentiate into the desired tissue within a porous scaffold and, as growth continues, the degrading scaffold would bear less of the mechanical load as the nascent bone bore an increasing amount. Here we have demonstrated a system that has the potential to achieve these goals. Scaffolds were computationally designed to be optimal for bearing load and allowing tissue ingrowth and then manufactured from a degradable polymer, PPF, reinforced with a ceramic, $\beta$-TCP. When these scaffolds were seeded with fibroblasts transduced to express BMP-7 and implanted subcutaneously, organized bone with marrow formed in and around the scaffold. Over increasing implantation times, the amount of bone and its compressive modulus both increased as the scaffold degraded. Key to achieving these results was combined the advantages of topology optimization, free-form fabrication of a ceramic-reinforced degradable polymer, and ex vivo gene therapy.

Topology optimization allows great flexibility in altering hierarchical pores for various purposes, such as to create wide-open channels in the macrostructure to allow initial mass exchange and small pores in the microstruc- tural architecture to maintain required porosity for blood vessel invasion but still retain mechanical integrity. Unlike traditional techniques, which create porous scaffolds by the use of porogens such as sodium chloride, the size and distribution of the pores of topology-optimized scaffolds are the outcome of computational results, rather than predetermined by a porogen. Reconstructions from our $\mu \mathrm{CT}$ data confirm that the design does perform as expected, in that we observed a bone formation ront that moved with increasing implantation times (Fig. 3). The front moved from the top of the center well until it coalesced with the infiltration of bone tissue from small pores to complete the full bone ingrowth. It is possible that the observed concentric-like patterns allowed the invasion of blood vessels (Fig. 2). It is also possible, however, that these channels were created by bone resorption triggered by lack of mechanical stimulation in the subcutaneous site. Whether these patterns will be affected by the design or be dominated by the loading milieu is not yet known.

The second key component of the approach described in this article was the use of the composite $\mathrm{PPF} / \beta$-TCP material. PPF/ $\beta$-TCP has been shown to be highly osteoconductive $\mathrm{e}^{37}$ and the work presented here confirms this in that bone formation was highly localized along the designed contours when scaffolds were seeded with transduced fibroblasts (Figs. 2 and 3). However, because no bone was observed on scaffolds seeded with untreated fibroblasts, it is clear that the osteoinductivity of this system derives from the presence of BMP-7 secreted by the transduced fibroblasts. Manipulating tissue aterial affin- 
ity through the addition of particles, such as the ceramic used here, helped direct bone ingrowth into pores as small as $400 \mu \mathrm{m}$ in diameter. The combination of topology-optimized designs with osteoconductive biodegradable polymer composite can fulfill the goal of load bearing at the initial stage as a suitable tissue-engineering strategy.

Finally, the use of ex vivo gene therapy enabled the production of large amounts of biologically and mechanically functional tissue without the use of specific progenitor cells. Further, the use of transduced fibroblasts allowed osteogenesis to commence quickly and fill the designed void space with organized bone tissue and marrow (Fig. 3). Therapeutically, autologous fibroblasts represent an easily biopsied source of immunocompatible cells that can be manipulated in vitro to express the desired transgene. When combined with an optimally designed scaffold of appropriate material composition, the transduced primary cells can combine with host cells to generate large amounts of functional tissue. ${ }^{38}$ Adenoviral vectors, such as those utilized in this study, do present certain safety concerns, particularly immmunogenicity of the virus. ${ }^{46,47}$ However, in the ex vivo approach we employed, cells transduced in vitro, rather than viral particles, are implanted, which may minimize the immune response. Further, the technique of seeding optimized scaffolds with transduced cells may be equally effective when used in conjunction with the newer, safer gene therapy vectors currently being developed. ${ }^{48,49}$

This combined approach has brought us a step closer to realizing the theoretical goal of using scaffolds in tissue engineering: a degradable biomaterial that allows functional tissue regeneration while retaining its overall mechanical properties as the scaffold degrades with reduced support resistance. In this idealized system, the scaffold provides initial function in the tissue defect and, as the scaffold material degrades, nascent bone increasingly compensates for the loss of mechanical function, allowing maintenance of a constant stiffness within the range of normal tissue. ${ }^{10}$ Although our results do not fully duplicate this idealized scenario, they do show that the combined bone-scaffold construct had nearly constant mechanical properties from weeks 2 through 12, as the scaffold degraded and bone formed. The designed topology-optimized PPF/ $\beta$-TCP scaffolds degraded with a stiffness dropping nearly to $60 \mathrm{MPa}$. The declining stiffness of the scaffold was reinforced by the growing bone tissue, and the stiffness of the construct remained at a plateau level between 60 and $70 \mathrm{MPa}$, which is within the range of human trabecular bone, ${ }^{50}$ until apparent bone resorption occurred at 12 weeks because of the lack of sufficient mechanical stimulation in the subcutaneous site (Fig. 4).

In summary, by integrating advantages of topologyoptimized design, biodegradable osteoconductive composite, and ex vivo gene therapy, we can achieve rapid osteogenesis and retain the stiffness of constructs to perform mechanical functions through the degradation time, even for ectopic implantations. These results show that this approach has potential for application in orthotopic sites with load-bearing demands such as segmental fracture healing and spine arthrodesis.

\section{ACKNOWLEDGMENTS}

Supported by grant NIH DE 13608 (ARP). We would like to thank Colleen Flanagen and Erin Wilke.

\section{REFERENCES}

1. Boden, S.D., Zdeblick, T., Sandhu, H.S., and Heim, S. The use of rhBMP-2 in interbody fusion cages: Definitive evidence of osteoinduction in humans - a preliminary report. Spine 25, 376, 2000.

2. Steinmann, J.C., and Herkowitz, H.N. Pseudarthrosis of the spine. Clin. Orthop. Relat. Res. 284, 80, 1992.

3. Summers, B.N., and Eisenstein, S.M. Donor site pain from the ilium: A complication of lumbar spine fusion. $\underline{\text { J. Bone }}$ Joint Surg. Br. 71, 677, 1989.

4. Cowley, S.P., and Anderson, L.D. Hernias through donor sites for iliac-bone grafts. J. Bone Joint Surg. Am. 65, 1023, 1983.

5. Banwart, J.C., Asher, M.A., and Hassanein, R.S. Iliac crest bone graft harvest donor site morbidity: A statistical evaluation. Spine 20, 1055, 1995.

6. Friedlaender, G. Immune responses to osteochondral allografts: Current knowledge and future directions. Clin. Orthop. Relat. Res. 174, 58, 1983.

7. Winn, S.R., Uludag, H., and Hollinger, J.O. Carrier systems for bone morphogenetic proteins. Clin. Orthop. Relat. Res. 367(Suppl.), S95, 1999.

8. Hollinger, J.O., and Leong, K. Poly ( $\alpha$-hydroxy acids): Carriers for bone morphogenetic proteins. Biomaterials 17, 187, 1996.

9. Langer, R., and Vacanti, J.P. Tissue engineering. Science 260, 920, 1993.

10. Hutmacher, D.W. Scaffold design and fabrication technologies for engineering tissues: State of the art and future perspectives. J. Biomater. Sci. Polym. Ed. 12, 107, 2001.

11. Simske, S., Ayers, R., and Bateman, T. Porous materials for bone regeneration. Mater. Sci. Forum 250, 151, 1997.

12. Vats, A., Tolley, N.S., Polak, J.M., and Gough, J.E. Scaffolds and biomaterials for tissue engineering: A review of clinical applications. Clin. Otolaryngol. 28, 165, 2003.

13. Hollister, S.J., Maddox, R.D., and Taboas, J.M. Optimal design and fabrication of scaffolds to mimic tissue properties and satisfy biological constraints. Biomaterials 23, 4095, 2002.

14. Mikos, A., Thorsen, A., Czerwonka, L., Bao, Y., and Langer, R. Preparation and characterisation of poly(L-lactic acid) foams. Polymer 35, 1068, 1994.

15. Mooney, D.J., Baldwin, D.F., Suh, N.P., Vacanti, J.P., and Langer, R. Novel approach to fabricate porous sponges of 
poly(D,L-lactic-co-glycolic acid) without the use of organic solvents. Biomaterials 17, 1417, 1996.

16. Cima, L.G., Vacanti, J.P., Vacanti, C., Ingber, D., Mooney, D., and Langer, R. Tissue engineering by cell transplantation using degradable polymer substrates. J. Biomech. Eng. 113, 143, 1991.

17. Lo, H., Ponticiello, M., and Leong, K. Fabrication of controlled release biodegradable foams by phase separation. Tissue Eng. 1, 15, 1995.

18. Thompson, R., Yaszemski, M., Powers, J., and Mikos, A. Fabrication of biodegradable polymer scaffolds to engineering trabecular bone. J. Biomater. Sci. Polym. Ed. 7, 23, 1995.

19. Whang, K., Thomas, C., Nuber, G., and Healy, K. A novel method to fabricate bioabsorbable scaffolds. Polymer 36, 837, 1995.

20. Hsu, Y.Y., Gresser, J.D., Trantolo, D.J., Lyons, C.M., Gangadharam, P.R., and Wise, D.L. Effect of polymer foam morphology and density on kinetics of in vitro controlled release of isoniazid from compressed foam matrices. J. Biomed. Mater. Res. 35, 107, 1997.

21. Yannas, I., Burke, J., Gordon, P., Huang, C., and Rubenstein, R. Design of an artificial skin. II. Control of chemical composition. Biomaterials 14, 107, 1980.

22. Vunjak-Novakovic, G., and Freed, L.E. Culture of organized cell communities. Adv. Drug Deliv. Rev. 33, 15, 1998.

23. Ishaug-Riley, S.L., Crane, G.M., Gurlek, A., Miller, M.J., Yasko, A.W., Yaszemski, M.J., and Mikos, A.G. Ectopic bone formation by marrow stromal osteoblast transplantation using poly(D,L-lactic-co-glycolic acid) foams implanted into the rat mesentery. J. Biomed. Mater. Res. 36, $1,1997$.

24. Guyton, A., and Hall, J. Textbook of Medical Physiology. Philadelphia: W.B. Saunders, 1996.

25. Martin, I., Padera, R.F., Vunjak-Novakovic, G., and Freed, L.E. In vitro differentiation of chick embryo bone marrow stromal cells into cartilaginous and bone-like tissues. J. Orthop. Res. 16, 181, 1998.

26. Lin, C.Y., Hsiao, C.C., Chen, P.Q., and Hollister, S.J. Interbody fusion cage design using integrated global layout and local microstructure topology optimization. Spine 29, 1747, 2004.

27. Lin, C.Y., Lin, C., and Hollister, S.J. A new approach for designing biodegradable bone tissue augmentation devices by using degradation topology optimization. Presented at the 8th World Multiconference on Systemics, Cybernetics and Informatics, Orlando, FL, July 18-21, 2004.

28. Bendsoe, M.P. Optimization of Structural Topology, Shape, and Material. New York: Springer-Verlag, 1995.

29. Kikuchi, N., and Suzuki, K. A homogenization method for shape and topology optimization. Comput. Methods Appl. Mech. Eng. 93, 291, 1991.

30. Sachlos, E., and Czernuszka, J.T. Making tissue engineering scaffolds work: The application of solid freeform fabrication technology to the production of tissue engineering scaffolds [review]. Eur. Cell Mater. 5, 29, 2003.

31. Taboas, J.M., Maddox, R.D., Krebsbach, P.H., and Hollister, S.J. Indirect solid free form fabrication of local and global porous, biomimetic and composite $3 \mathrm{D}$ polymer-ceramic scaffolds. Biomaterials 24, 181, 2003.
32. Bose, S., Darsell, J., Hosick, H., Yany, L., Sarrkar, D., and Bandyopahhyay, A. Processing and characterization of porous alumina scaffolds. J. Mater. Sci. 13, 23, 2002.

33. Chu, T.M., Hollister, S.J., Halloran, J.W., Feinberg, S.E., and Orton, D.G. Manufacturing and characterization of 3-D hydroxyapatite bone tissue engineering scaffolds. Ann. N.Y. Acad. Sci. 961, 114, 2002.

34. Frazier, D.D., Lathi, V.K., Gerhart, T.N., Altobelli, D.E., and Hayes, W.C. In vivo degradation of a poly(propylenefumarate) biodegradable particulate composite bone cement. MRS Proc. 349, 5, 1995.

35. Yaszemski, M.J., Payne, R.G., Haynes, W.C., Langer, R., and Mikos, A.G. In vitro degradation of a poly(propylene fumarate)-based composite material. Biomaterials 17, 2127, 1996.

36. Peter, S.J., Miller, S.T., Zhu, G., Yasko, A.W., and Mikos, A.G. In vivo degradation of a poly(propylene fumarate) $/ \beta$ tricalcium phosphate injectable composite scaffold. J. Biomed. Mater. Res. 41, 1, 1998.

37. Peter, S.J., Lu, L., Kim, D.J., and Mikos, A.G. Marrow stromal osteoblast function on a poly(propylene fumarate) $/ \beta$-tricalcium phosphate biodegradable orthopaedic composite. Biomaterials 21, 1207, 2000.

38. Krebsbach, P.H., Gu, K., Franceschi, R.T., and Rutherford, R.B. Gene therapy-directed osteogenesis: BMP-7-transduced human fibroblasts form bone in vivo. Hum. Gene Ther. 11, 1201, 2000.

39. Gazit, D., Turgeman, G., Kelley, P., Wang, E., Jalenak, M., Zilberman, Y., and Moutsatsos, I. Engineered pluripotent mesenchymal cells integrate and differentiate in regenerating bone: A novel cell-mediated gene therapy. J. Gene Med. 1, 121, 1999.

40. Lieberman, J.R., Le, L.Q., Wu, L., Finerman, G.A., Berk, A., Witte, O.N., and Stevenson, S. Regional gene therapy with a BMP-2-producing murine stromal cell line induces heterotopic and orthotopic bone formation in rodents. J. Orthop. Res. 16, 330, 1998.

41. Rutherford, R.B., Moalli, M., Franceschi, R.T., Wang, D., $\mathrm{Gu}, \mathrm{K}$., and Krebsbach, P.H. Bone morphogenetic proteintransduced human fibroblasts convert to osteoblasts and form bone in vivo. Tissue Eng. 8, 441, 2002.

42. Schek, R.M., Taboas, J.M., Hollister, S.J., and Krebsbach, P.H. Engineered osteochondral grafts using biphasic composite solid free form fabricated scaffolds. Tissue Eng. 10, 1376, 2004.

43. Shung, A.K., Timmer, M.D., Jo, S., Engel, P.S., and Mikos, A.G. Kinetics of poly(propylene fumarate) synthesis by step polymerization of diethyl fumarate and propylene glycol using zinc chloride as a catalyst. J. Biomater. Sci. Polym. Ed. 13, 95, 2002.

44. Rutherford, R.B., TrailSmith, M.D., Ryan, M.E., and Charette, M.F. Synergistic effects of dexamethasone on platelet-derived growth factor mitogenesis in vitro. Arch. Oral Biol. 37, 139, 1992.

45. Franceschi, R.T., Wang, D., Krebsbach, P.H., and Rutherford, R.B. Gene therapy for bone formation: In vitro and in vivo osteogenic activity of an adenovirus expressing BMP7. J. Cell Biochem. 78, 476, 2000.

46. Check, E. A tragic setback. Nature 420, 116, 2002.

47. Raper, S.E., Yudkoff, M., Chirmule, N., Gao, G.P., Nunes, F., Haskal, Z.J., Furth, E.E., Propert, K.J., Robinson, M.B., 
Magosin, S., Simoes, H., Speicher, L., Hughes, J., Tazelaar, J., Wivel, N.A., Wilson, J.M., and Batshaw, M.L. A pilot study of in vivo liver-directed gene transfer with an adenoviral vector in partial ornithine transcarbamylase deficiency. Hum. Gene Ther. 13, 163, 2002.

48. Dettweiler, U., and Simon, P. Points to consider for ethics committees in human gene therapy trials. Bioethics 15, 491, 2001.

49. Lundstrom, K. Latest development in viral vectors for gene therapy. Trends Biotechnol. 21, 117, 2003.

50. Goulet, R.W., Goldstein, S.A., Ciarelli, M.J., Kuhn, J.L., Brown, M.B., and Feldkamp, L.A. The relationship be- tween the structural and orthogonal compressive properties of trabecular bone. J. Biomech. 27, 375, 1994.

Address reprint requests to: Scott J. Hollister, Ph.D. 2200 Bonisteel Boulevard Department of Biomedical Engineering University of Michigan Ann Arbor, MI 48109

E-mail: scottho@umich.edu 


\section{This article has been cited by:}

1. Seth D. McCullen, Sangeetha Ramaswamy, Laura I. Clarke, Russell E. Gorga. 2009. Nanofibrous composites for tissue engineering applications. Wiley Interdisciplinary Reviews: Nanomedicine and Nanobiotechnology 1:4, 369-390. [CrossRef]

2. Sara M. Mantila Roosa, Jessica M. Kemppainen, Erin N. Moffitt, Paul H. Krebsbach, Scott J. Hollister. 2009. The pore size of polycaprolactone scaffolds has limited influence on bone regeneration in an in vivo model. Journal of Biomedical Materials Research Part $A$ 9999A, NA-NA. [CrossRef]

3. Meghan J. Cuddihy, Nicholas A. Kotov . 2008. Poly(lactic-co-glycolic acid) Bone Scaffolds with Inverted Colloidal Crystal GeometryPoly(lactic-co-glycolic acid) Bone Scaffolds with Inverted Colloidal Crystal Geometry. Tissue Engineering Part A 14:10, 1639-1649. [Abstract] [PDF] [PDF Plus]

4. Safdar N. Khan, Jorge Solaris, Keri E. Ramsey, Xu Yang, Mathias P. G. Bostrom, Dietrich Stephan, Aaron Daluiski. 2008. Identification of Novel Gene Expression in Healing Fracture Callus Tissue by DNA Microarray. HSS Journal 4:2, 149-160. [CrossRef]

5. Shiwei Zhou, Qing Li. 2008. Design of graded two-phase microstructures for tailored elasticity gradients. Journal of Materials Science 43:15, 5157-5167. [CrossRef]

6. M. H. Smith, C. L. Flanagan, J. M. Kemppainen, J. A. Sack, H. Chung, S. Das, S. J. Hollister, S. E. Feinberg. 2007. Computed tomography-based tissue-engineered scaffolds in craniomaxillofacial surgery. The International Journal of Medical Robotics and Computer Assisted Surgery 3:3, 207-216. [CrossRef]

7. Elly Liao, Michael Yaszemski, Paul Krebsbach, Scott Hollister . 2007. Tissue-Engineered Cartilage Constructs Using Composite Hyaluronic Acid/Collagen I Hydrogels and Designed Poly(Propylene Fumarate) Scaffolds. Tissue Engineering 13:3, 537-550. [Abstract] [PDF] [PDF Plus]

8. N Kimelman, G Pelled, Zul Gazit, D Gazit. 2006. Applications of gene therapy and adult stem cells in bone bioengineering. Regenerative Medicine 1:4, 549-561. [CrossRef] 